DOi: $10.38136 /$ jgon.639823

\title{
Yenidoğan Yoğun Bakım Ünitesinde Trakeostomi Uygulamaları
}

\section{Tracheostomy in Neonatal Intensive Care Unit}

\author{
Șehribanu IȘIK \\ Evrim ALYAMAÇ DIZDAR \\ Handan BEZIRGANOĞLU \\ Nurdan URAȘ \\ Murat ERAY IȘIK \\ Serife SUNA OĞUZ \\ Ömer ERTEKIN
}

(1) orcid id:0000-0002-3368-1514

(1) orcid id:0000-0001-5914-5325

(1) orcid id:0000-0002-9409-185X

(1) orcid id:0000-0002-9970-0714

(1) orcid id:0000-0002-9409-185X

(1) orcid id:0000-0002-9970-0714

(1) orcid id:0000-0002-9970-0714

\footnotetext{
${ }^{1}$ Ankara Șehir Hastanesi, Yenidoğan Kliniği, Ankara

2 Diyarbakır Gazi Yașargil Eğitim ve Araștırma Hastanesi, Yenidoğan Kliniği, Diyarbakır

3 İstinye Üniversitesi Hastanesi, Yenidoğan Kliniği, İstanbul

${ }^{4}$ Dıșkapı Yıldırım Beyazıt Eğitim ve Araștırma Hastanesi, Kulak Burun Boğaz Kliniği, Ankara
}

\section{ÖZ}

Amaç: Bu çalışmada ünitemizde trakeostomi açılıış olan hastaların endikasyonları, erken ve uzun dönem sonuçlarının belirlenmesi amaçlanmıştır.

Gereçler ve Yöntem: Bu çalışmada Ocak 2013- Aralık 2015 arasında Zekai Tahir Burak Kadın Sağlığı Eğitim Araştırma Hastanesi Yenidoğan Yoğun Bakım Ünitesi'nde (YYBÜ) izlenen ve trakeostomi açılmış olan 11 hastanın geriye dönük kayıtları incelenmiștir. Hastaların gestasyonel yaşları, doğum ağırıkları, trakeostomi endikasyonları, trakeostomi öncesi entübe kaldıkları gün sayısı, komplikasyonlar, eşlik eden sorunlar, mortalite oranları, mevcut klinik durumları kaydedilmiştir.

Bulgular: Hastaların gestasyon yaşı ortanca 32 hafta, doğum ağırlığı $1470 \mathrm{gr} \mathrm{idi}$. Trakeostomi öncesi entübe kalma süresi ortanca 130 gün idi. Trakeostomi açıma günü ortanca 73 gün olarak saptandı. Trakeostomi açılma sebepleri 1 hastada konjenital laringeal anomali, dört hastada prematürite komplikasyonları (bronkopulmoner displazi, subglottik stenoz), üç hastada nöromüsküler güçsüzlük (asfiksi, metabolik hastalık, myotonik distrofi), bir hastada Beckwith-Wideman sendromu, bir hastada artrogyropozis multipleks, bir hastada Arnold-Chiari malformasyonu nedeniyle uzamış mekanik ventilasyon idi. Trakeostomi sonrası üç (\%27) hasta mekanik ventilatörden ayrıldı. Bu hastalarda mekanik ventilatörden ayrılma süresi ortanca 12 gün olarak saptandı. Ortanca hospitalizasyon süresi 180 gün olup sekiz hasta (\%73) takip süresince primer hastalıkları nedeniyle kaybedildi. İki (\%18) hasta taburcu edildi. İki hastaya kazara dekanulasyon nedeniyle, bir hastaya da stomal striktür nedeniyle olmak üzere hastaların üçüne (\%27) ikinci kez trakeostomi açılması gerekti. Bir hastanın taburculuk sonrası izleminde trakeostomisi kapatılı.

Sonuç: Erken dönemde YYBÜ intiyacı olup, farklı sebeplerle uzun süreli entübasyon ihtiyacı olan hastaların, trakeostomi endikasyonu açısından değerlendirilmesi uygun bir yaklaşım olacaktır.

Anahtar Sözcükler: Komplikasyonlar, trakeostomi, yenidoğan, yoğunbakım

\section{ABSTRACT}

Aim: The aim of this study was to determine the tracheostomy indications and early and long term outcomes.

Materials and Method: In this study, clinical records of 11 tracheostomy cases at Zekai Tahir Burak Maternity and Teaching Hospital NICU between January 2013 and December 2015 were reviewed retrospectively. Gestational ages, birth weights, tracheostomy indications, duration of mechanical ventilation before tracheostomy, complications, comorbidities, mortality rate, and actual clinical conditions of the infants were recorded.

Results: Median gestational age was 32 weeks, and median birth weight was $1470 \mathrm{~g}$. Median duration of mechanical ventilation was 130 days. Age on tracheostomy was median 73 days. The indications were congenital laryngeal anomaly; and prolonged mechanical ventilation due to complications of prematurity (bronchopulmonary dysplasia, subglottic stenosis), neuromuscular weakness (asphxia, metabolic disorder, myotonic dystrophy), Beckwith-Wideman syndrome, artrogyropozis multiplex, Arnold-Chiari malformation. After tracheostomy, 3 (27\%) patients were weaned from mechanical ventilatory support, median duration of weaning was 12 days. The length of hospitalization was median 180 days and eight infants (73\%) died before they were discharged. Two (18\%) infants were discharged from the hospital. Tracheostomy was revised due to accidental decannulation and stomal stricture in $3(27 \%)$ patients. Decannulation was possible in one patient after discharge from the hospital.

Conclusion: It would be appropriate to evaluate infants in terms of tracheostomy indication who require long-term intubation for different reasons in NICU.

Keywords: Complications, tracheostomy, newborn, intensive care unit

\section{GíRiş}

Pediyatrik trakeostomi insidansı ve endikasyonları zaman içerisinde değişime uğramıştır. Enfeksiyona sekonder üst hava yolu obstrüksiyonu eskiden en sık endikasyon iken, günümüzde yoğun bakım şartlarının gelişmesi ile yerini uzamış mekanik ventilatör intiyacına bırakmıştır $(1,2)$.
Erken surfaktan tedavisi, yeni ventilatör stratejileri, artmış noninvazif pozitif basınçı ı ventilasyon kullanımına rağmen, bronkopulmoner displazi (BPD) prematüre doğumların halen önemli bir komplikasyonunu oluşturmaktadır.

Sorumlu Yazar/ Corresponding Author:

Şehribanu IŞIK

Ankara Şehir Hastanesi Üniversiteler Mahallesi Bilkent Cad. No:1 Çankaya/ ANKARA

E-mail: sbanuozluer@hotmail.com 
Aşırı düşük doğum ağırlıkı ve çok düşük doğum ağılıklı bebeklerin yaşam oranının artması, artmış BPD oranına katkı sağlamaktadır (3). Ayrıca, konjenital anomalili hasta term bebeklerin bakımı da ilerlemiştir. Bu infantların çoğunda uzamış mekanik ventilasyon gereksinimi olmaktadır. Bazı infantlarda da konjenital havayolu anomalileri nedeniyle trakeostomi gerekmektedir $(4,5)$.

Çalışmalarda uzun süreli entübe infantlarda erken trakeostomi ile subglottik ve trakeal stenoz insidansının azaldığı saptanmıştır. Ek olarak, trakeostomi ile artmış konfor, sedasyon ihtiyacında azalma, sistemik kortikosteroid maruziyetinde azalma, artmış beslenme ve büyüme, oral beslenmeye artmış uyum sağlanmaktadır. Ayrıca kronik respiratuar yetmezlikli hastalarda evde mekanik ventilasyon olanağı sağlar. Böylece pediatrik yoğun bakım ve hastanede yatış süresini azaltır (6). Trakeostomi oranı \%0.55- \%2.7 arasında değişmektedir.

Pediyatrik trakeostomiler ile ilgili çalışmalar genellikle cerrahi endikasyonlar ve kullanılan teknikle ilgilidir (7). Komplikasyonlar ve uzun dönem sonuçlarla ilgili az sayıda çalışma mevcuttur (8). Literatürdeki çoğu veri 2004 yılı öncesine ait olup o dönemde yeni ventilatör stratejileri klinik uygulamada kullanımamakta idi. Son 20 yılda, yenidoğan yoğunbakım ünitelerinde (YYBÜ) kritik hasta bakımında solunumsal bakım ve tedavi yöntemlerinde önemli iyileşmeler kaydedilmiştir.

Bu araştırmada yılda ortalama 18.000 doğumun gerçekleştiği hastanemizin üçüncü basamak bakım veren yenidoğan yoğun bakım ünitesinde iki yıllık süre içinde trakeostomi açılmış olan hastaların erken ve uzun dönem sonuçlarının belirlenmesi amaçlanmıştır.

\section{GEREÇ VE YÖNTEMLER}

Bu çalışmada Ocak 2013-Aralık 2015 arasında Zekai Tahir Burak EAH YYBÜ' nde izlenen ve uzun süreli ventilasyon intiyacı nedeniyle trakeostomi açılmış olan 11 hastanın retrospektif kayıtları incelendi. Hastaların gestasyonel yaşları, doğum ağırlıkları, tanıları, trakeostomi öncesi entübe kaldıkları gün sayıları, prosedür öncesi ekstübasyon başarısızığı sayısı, trakeostomi sırasındaki ağılıkları, postnatal yaşları, eşlik eden sorunlar, ekstübasyon oranları, ekstübe olma süreleri, ilişkili morbiditeler, erken komplikasyonlar, mortalite, dekanülasyon zamanı, ev ventilasyon gereksinimleri ve sonuçları kaydedildi. Trakeostomilerin tamamı Kulak Burun Boğaz (KBB) uzmanı tarafından ameliyathanede entübe şekilde genel anestezi altında gerçekleştirildi. Preoperatif tam kan sayımı, hemostaz belirteçleri, akciğer grafisi tetkikleri tüm hastalara yapıııp, ailelerden ayrıntıı olarak hazırlanmış onam formları alındı. Bu çalışma, Zekai Tahir Burak Kadın Sağlığı Eğitim ve Araştırma Hastanesi yerel Etik Komitesi tarafından etik açıdan onaylandı (2015/7).

Trakeaya erişim için uygun pozisyon sağlamak üzere için hastalara omuz altı desteği ile pozisyon verildi. Cerrahi alan sterilizasyonunu takiben, krikoid kartilaj alt sınırı hizasında ve her iki sternokloidomastoid kasa (SCM) ulaşan horizontal deri insizyonu yapıldı. Cilt altı ve strep kaslar geçildi ve gerekli olduğu durumda tiroid istmus bağlanarak ekarte edildi. Superiorda krikoid kartilaj, inferiorda 4. ve 5. Trakeal halkalar görülecek şekilde diseksiyon uygulandı. 3. ve 4. trakeal halkalar arasına 3/0 ipek sütürler ile askı sütürleri yerleştirilmesini takiben, 2. ve 3. trakeal kartilajlara vertical planda kesi yapılarak orotrakeal entübasyon tüpü çıkarılıp hastanın trakea çapı ve karina yüksekliğiyle uyumlu portex kanül yerleştirildi. Tüm hastalar işlem sonrası akciğer grafisi ve arteriyel kan gazı ile değerlendirildi.

Elde edilen veriler SPSS 20 (Statistical Package for Social Sciences; Chicago, IL, ABD) programı kullanıldı ve ortanca, yüzde, frekans değerleri analiz edildi.

\section{BULGULAR}

Ocak 2013- Aralık 2015 arasında kliniğimizde takip edilen 7950 hastadan trakeostomi açılmış olan toplam 11 hastanın verilerine ulaşıldı. Trakeostomi oranı \% 0,13 saptandı. Hastaların gestasyon yaşı ortanca (IQR) 32 hafta (27-37), doğum ağırlı̆ı 1470 gr (940-2150) idi. Trakeostomi öncesi entübe kalma süresi ortanca (IQR) 130 gün (80-210), trakeostomi açılma günü ortanca (IQR) 73 (43-111) gün, trakeostomi açıldığındaki vücut ağırlığı ortanca (IQR) 3100 gr (2500-4420) saptandı. Hastaların genel özellikleri Tablo 1'de verilmiştir.
Tablo 1. Hastaların Genel özellikleri, Tanıları, Eşlik eden sorunlar

\begin{tabular}{|c|c|c|c|c|c|}
\hline Sayı & $\begin{array}{c}\text { Doğum } \\
\text { ağırlığı } \\
\text { (gr) }\end{array}$ & $\begin{array}{c}\text { Gestasyon yaşı } \\
\text { (hafta) }\end{array}$ & $\begin{array}{l}\text { Mekanik ven- } \\
\text { tilasyon süresi } \\
\text { (gün) }\end{array}$ & Tanı & Eşlik eden sorunlar \\
\hline 1 & 550 & 23 & 270 & PM, BPD & GÖR, ROP \\
\hline 2 & 770 & 30 & 80 & PM & İK, VSD \\
\hline 3 & 940 & 27 & 290 & PM, SP, BPD & $\begin{array}{l}\text { GÖR, yutma disfonksiyonu, } \\
\text { ROP, nöbet }\end{array}$ \\
\hline 4 & 970 & 26 & 118 & PM & \\
\hline 5 & 1300 & 29 & 1 & Laringeal anomali & \\
\hline 6 & 1470 & 36 & 210 & Metabolik hastalık & $\begin{array}{c}\text { GÖR, ensefalopati, yutma dis- } \\
\text { fonksiyonu }\end{array}$ \\
\hline 7 & 1880 & 35 & 128 & Myotonik distrofi & GÖR, yutma disfonksiyonu \\
\hline 8 & 2030 & 37 & 167 & $\begin{array}{l}\text { Artrogripozis } \\
\text { multipleks }\end{array}$ & $\begin{array}{l}\text { Yutma disfonksiyonu, } \\
\text { Beslenme güçlüğü }\end{array}$ \\
\hline 9 & 2510 & 32 & 130 & Beckwith wideman & İnkontinentia pigmenti \\
\hline 10 & 2515 & 38 & 43 & Asfiksi & $\begin{array}{l}\text { Yutma disfonksiyonu, } \\
\text { ensefalopati, nöbet }\end{array}$ \\
\hline 11 & 3180 & 39 & 187 & MMS, hidrosefali & $\begin{array}{l}\text { GÖR, VP sant, nöbet, yutma } \\
\text { disfonksiyonu }\end{array}$ \\
\hline
\end{tabular}

PM: Prematüre, BPD: Bronkopulmoner displazi, GÖR: Gastroözefageal reflü, ROP: prematüre retinopatisi, IKK: intrakranial kanama, VSD: Ventriküler septal defekt SP: serebral palsi, MMS: Meningomyelosel, VP: Ventriküloperitoneal

Trakeostomi açılma sebepleri bir hastada konjenital laringeal anomali, dört hastada prematürite komplikasyonları (BPD, subglottik stenoz), üç hastada nöromüsküler güçsüzlük (asfiksi, metabolik hastalık, myotonik distrofi), bir hastada Beckwith-Wideman sendromu, bir hastada artrogyropozis multipleks, bir hastada Arnold-chiari malformasyonu nedeniyle uzamış mekanik ventilasyon idi (Tablo 2).

Tablo 2. Hastaların trakeostomi sırasındaki kilo, yaşları; trakeostomi endikasyonları, komplikasyon ve sonuçları

\begin{tabular}{|ccccccc}
\hline Sayı & $\begin{array}{c}\text { Kilo } \\
\text { (gr) }\end{array}$ & $\begin{array}{l}\text { Yaş } \\
\text { (gün) }\end{array}$ & Endikasyon & Komplikasyon & $\begin{array}{c}\text { Mekanik } \\
\text { ventilatörden } \\
\text { ayrilma }\end{array}$ & Sonuç \\
\hline $\mathbf{1}$ & 2500 & 118 & BPD & $\begin{array}{c}\text { Kazara dekanu- } \\
\text { lasyon, revizyon }\end{array}$ & yok & $\begin{array}{l}\text { 280. günde MV ile } \\
\text { taburcu }\end{array}$ \\
\hline $\mathbf{2}$ & 1800 & 70 & BPD & yok & 84. günde eksitus \\
\hline $\mathbf{3}$ & 3100 & 111 & BPD & $\begin{array}{c}\text { Kazara dekanu- } \\
\text { lasyon, revizyon }\end{array}$ & yok & 350. günde eksitus \\
\hline $\mathbf{4}$ & 2500 & 105 & Subglottik stenoz & var & $\begin{array}{l}\text { 21. günde taburcu, } \\
\text { Dekanulasyon }\end{array}$ \\
\hline $\mathbf{5}$ & 1300 & 1 & Laringeal anomali & yok & 1. günde eksitus \\
\hline
\end{tabular}

\begin{tabular}{|c|c|c|c|c|c|c|}
\hline 6 & 5100 & 190 & $\begin{array}{l}\text { Nöromuskuler } \\
\text { güçsüzlük }\end{array}$ & & yok & 210. günde eksitus \\
\hline 7 & 4150 & 73 & $\begin{array}{l}\text { Nöromuskuler } \\
\text { güçsüzlük }\end{array}$ & & yok & 128. günde eksitus \\
\hline 8 & 2500 & 30 & $\begin{array}{l}\text { Artrogripozis mul- } \\
\text { tipleks }\end{array}$ & & yok & 180. günde eksitus \\
\hline 9 & 5000 & 97 & $\begin{array}{l}\text { Beckwith Wideman } \\
\text { sendromu }\end{array}$ & & var & 165. günde eksitus \\
\hline 10 & 3500 & 43 & $\begin{array}{l}\text { Nöromuskuler } \\
\text { güçsüzlük }\end{array}$ & $\begin{array}{l}\text { Trakeal striktür, } \\
\text { revizyon }\end{array}$ & var & 207. günde hospitalize \\
\hline 11 & 4420 & 68 & $\begin{array}{c}\text { Arnold Chiari mal- } \\
\text { formasyonu }\end{array}$ & & yok & 220. günde eksitus \\
\hline
\end{tabular}

BPD: Bronkopulmoner displazi

Trakeostomi sonrası üç (\%27) hasta mekanik ventilatörden ayrıldı. Bu hastalarda mekanik ventilatörden ayrılma süresi ortanca (IQR) 12 (4-40) gün olarak saptandı. Ortanca (IQR) hospitalizasyon süresi 180 (121-220) gün olup sekiz hasta (\%73) takip süresince primer hastalıkları nedeniyle kaybedildi. Doğum sonrası acil trakeostomi gereken laringeal anomalisi olan bir hasta postop erken dönemde; diğer yedi infant ilk 30 günden sonra kaybedildi. İki (\%18) hasta taburcu edildi. Bir hasta ev tipi mekanik ventilatör ile 280. günde ve bir hasta oksijen desteği olmadan 121. günde taburcu edildi. Hastaların üçüne (\%27) ikinci kez trakeostomi açılması gerekti, iki hastaya kazara dekanulasyon nedeniyle, bir hastaya striktür nedeniyle revizyon yapıldı. Bir hasta taburculuk sonrası izleminde ağız solunumuna geçtiği için trakeostomisi kapatıldı.

\section{TARTIŞMA}

Çalışmamızda en sık trakeostomi nedeni olarak uzamış entübasyon saptandı. Anestezi tekniklerinin gelişmesi sonucunda, endotrakeal entübasyonun güvenle ve uzun süreli yapılabilir oluşu ile solunum yolu enfeksiyonu nedeni ile açılan trakeostomilerde önemli oranda azalma olmuştur (9). Çalışmamızda üst solunum yolu enfeksiyonu nedeniyle trakeostomi uygulanan hasta yoktu.

Çocuklarda uzun süreli entübasyon endikasyonu olarak nöromusküler hastalıklar, konjenital anomaliler, metabolik hastalıklar yer almaktadır. Çalışmamızdaki hasta grubunda dört hastada prematürite komplikasyonları (BPD, subglottik stenoz), üç hastada nöromüsküler güçsüzlük (asfiksi, metabolik 
hastalık, myotonik distrofi), bir hastada Beckwith-Wideman sendromu, bir hastada artrogyropozis multipleks, bir hastada Arnold-chiari malformasyonu nedeniyle uzamış mekanik ventilasyon gereksinimi olduğu saptandı.

Cocuklarda trakeostomi işlemi ameliyathane şartlarında, genel anestezi altında, hasta entübe edildikten sonra yapılmalıdır (10). Trakea hareketli ve palpasyonu zor olduğundan erişkinlerdeki gibi perkütan dilatasyon yöntemi kullanılmaz. Çocuğun yaşı, trakeanın boyu ve genişliğine uygun trakeostomi kanülü ile seçilen kanülün bir numara küçüğü ve büyüğü işlem sırasında mutlaka hazır bulundurulur.

Yapılan bir çalışmada trakeostomi uygulanan çocukların izlemlerinde mortalite oranının \%41 olduğu bildirilmiştir. Bu ölümlerin çoğunlukla altta yatan hastalığa bağlı oluştuğu tespit edilmiştir (11). Onbir olguluk serimizde mortalite oranı $\% 73$ olarak tespit edildi ve laringeal anomalisi olan bir bebek dışındaki ölümlerin tümü trakeostomi sonrası altta yatan hastalığa bağlı olarak geç dönemde gelişti.

Trakeostomiye bağlı ölümcül komplikasyonlar genellikle ilk haftalarda gerçekleşen erken komplikasyonlardır. Literatürde trakeostomi ile ilişkili ölüm \%1'in altında bildirilmiştir (12). Bizim 11 hastamızda da trakeostomi işlemi başarıyla uygulanmış olup intraoperatif dönemde trakeostomiye bağı hasta kaybı olmamıştır.

Trakeostomi kanülünün yanlışlıkla yerinden çıkması ve hava kaçağı gibi erken dönem komplikasyonlar çeşitli serilerde \%53-61 gibi yüksek oranlarda bildirilmiştir (13). Trakeostominin ameliyathane şartlarında genel anestezi altında açılması ve akut enfeksiyon nedeniyle açılan acil trakeostomilerin azalması sonrasında pnömotoraks, pnömomediastinum gibi ciddi erken dönem komplikasyonlar son yıllarda azalmıştır. Kanülün yerinden çıkması önemli komplikasyonlardan biridir. Trakeostomi bakımı yapan personelin tecrübesizliği ve hastaların çok hareketli oluşu en önemli etkenlerdendir. Bu komplikasyonun önlenmesinde trakeaya yerleştirilen kılavuz sütürler hayati önem taşır (14). Bizim hasta grubumuzda trakeostomi komplikasyonu olarak iki hastada trakeostomi kanülünün yerinden çıkması görüldü. Trakeostomili hastaların izlemlerinde trakeostomi bölgesinde granülasyon dokusu gelişimi ya da ciltte skar dokusu nedeniyle daralma görülebilir. Bizim bir hastamızda da olduğu gibi bu durumlarda stomanın genişletilmesi gerekir. Trakeostomiye bağlı en ciddi komplikasyonlardan bir tanesi trakeal stenoz olup geç dönemde ortaya çıkar (15). Hastalarımızın hiçbirinde izlem süresince trakeal stenoz gelişmedi.

Hastaların takibinde trakeostomi açımasını gerektiren sorun düzeldiğinde trakeostominin kapatıması (dekanülasyonu) gündeme gelir. Bu süreçte trakeostomi kademeli olarak daraltıır ve sonunda tıkanır (16). Çocuk dekanülasyon için hazır olduğunda, hava yolunun açık olduğundan emin olmak için endoskopi yapıımalıdır. Çocuk trakeostomi tıkanmasını uyanık olduğu sürece tolere edebilirse dekanülasyon kararı verilir, çocuk hastaneye yatırılır ve trakeostomi kanülü, sürekli monitorizasyon ile gece boyunca tıkalı tutulur. Oksijen desatürasyonu veya apne oluşmazsa, ertesi sabah trakeostomi tüpü çıkarılır, stoma tıkayıcı bir pansumanla kaplanır ve çocuk tekrar sürekli monitorizasyon ile ek bir gece boyunca izlenir. Trakeostomi hattı genellikle 2-3 gün içinde kapanır (17). Kapanma sonrasında trakeokutanöz bir fistül gelişebilir. Fistül açıklığı altı ay veya daha fazla sürerse cerrahi onarım düşünülebilir (18).

Uzun süreli entübasyona bağlı trakeostomi açılan çocuklarda primer hastalık nedeniyle dekanülasyon oranı daha azdır (19). Bizim çalışmamızda da sadece bir hastamızda, taburculuk sonrası izlem sırasında tarkeostomi kapatılı.

Özellikle uzun süreli entübasyon gereken bakım hastaları trakeostomi sonrası, aile eğitimi verilerek taburcu edilebilmektedir. Evde izlenecek ve uzun süre trakeostomili kalacak çocuklar için trakeostomi bakımı, acil durumlarda yapılacaklar konusunda ebeveynlerden en az biri eğitilmelidir. Rutin ve acil müdahaleler için gerekli tüm malzemeler çocuğun etrafında bulundurulmalıdır. Ev ortamı çocuğun gereksinimlerine göre düzenlenmelidir. Aile, çocuk ve sağlık personeli arasında düzenli bir ilişki kurulmalıdır $(20,21)$. Bizim hasta grubumuzda bir hasta ev tipi mekanik ventilatör desteği ile taburcu edildi. Taburculuk öncesi anne ve babaya iki hafta boyunca eğitim verildi.

Çalışmamızda olgu sayısının azlığı kısıtlayıcı bir faktör olarak karşımıza çıkmaktadır. Ancak bu yaş grubunda trakeostomi çok sık uygulanan bir girişim değildir. Çalışmamızı destekleyecek geniş seriler oluşturmak için çok merkezli ve uzun süreli çalışmalara intiyaç vardır.

\section{SONUÇ}

Erken dönemde YYBÜ intiyacı olup, prematüriteye bağlı veya farklı sebeplerle uzun süreli entübasyon intiyacı olan hastaların, trakeostomi endikasyonu açısından değerlendirilmesi uygun bir yaklaşım olacaktır.

\section{REFERANSLAR}

1. Trachsel D, Hammer J. Indications for tracheostomy in children. Paediatr Respir Rev. Sep 2006; 7(3):162-8.

2. Kilic D, Findikcioglu A, Akin S, Korun O, Aribogan A, Hatiboglu A. When is surgical tracheostomy indicated? Surgical "U-shaped" versus percutaneous tracheostomy. Ann Thorac Cardiovasc Surg. 2011; 17(1):29-32.

3. Vakrilova L, Stancheva B, Dimitrov A, Nikolov A. The very low birth weight and very low gestational age neonates-survival, prognosis and perspectives [in Bulgarian]. Akush Ginekol (Sofiia). 2011;50(1):31-36

4. Estournet-Mathiaud B. Tracheostomy in chronic lung disease: care and follow-up. Pediatr Pulmonol. 2001;23(suppl 23):135-136

5. Keszler M. State of the art in conventional mechanical ventilation. J Perinatol. 2009; 29 (4):262-275

6. Baud O. Postnatal steroid treatment and brain development. Arch Dis Child Fetal Neonatal Ed. 2004;89(2): F96-F100

7. Pereira KD, MacGregor AR, Mitchell RB. Complications of neonatal tracheostomy: a 5-year review. Otolaryngol Head Neck Surg. 2004;131(6):810-813

8. Wheeler WB, Maguire EL, Kurachek SC, Lobas JG, Fugate JH, McNamara JJ. Chronic respiratory failure of infancy and child- hood: clinical outcomes based on un- derlying etiology. Pediatr Pulmonol. 1994;17 (1):1-5

9. Zadrobilek E, Mauritz W, Spiss C, Draxler V, Sporn P. Indications for tracheotomy in long-term ventilated critically ill patients. Anasth Intensivther Notfallmed 1984; 19: 19-23.

10. Akcan AB, Dursun O. Pediatrik trakeotomi ve ev bakımı. KBB-Forum 2010; 9: 70-7

11. Swift AC, Rogers JH. The changing indications for tracheostomy in children. J Laryngol Otol 1987; 101: 1258-62.

12. Rozsasi A, Kühnemann S, Gronau S, Keck T. A single-center 6-year experience with two types of pediatric tracheostomy. Int J Pediatr Otorhinolaryngol 2005; 69: 607-13.

13. Carr MM, Poje CP, Kingston L, Kielma D, Heard C. Complications in pediatric tracheostomies. Laryngoscope 2001; 111: 1925-8.

14. Koltai JP. Starplasty: a new technique of pediatric tracheotomy. Arch Otolaryngol Head Neck Surg 1998; 124: 1105-11.

15. Fry TL, Jones RO, Fischer ND, Pillsbury HC. Comparisons of tracheostomy incisions in a pediatric model. Ann Otol Rhinol Laryngol 1985; 94: 450-3.

16. Runton N, Zalzal GH: The decannulation process in children. J Pediatr Nurs 1989; 4:370.

17. Waddell A, Appleford R, Dunning C, Papsin BC, Bailey CM. The Great Ormond Street protocol for ward decannulation of children with tracheostomy: increasing safety and decreasing cost. Int J Pediatr Otorhinolaryngol 1997; 39(2): 111-18.

18. Stern Y, Cosenza M, Walner D, Cotton RT. Management of persistent tracheocutaneous fistula in the pediatric age group. Ann Otol Rhinol Laryngo 1999;108(9): 880-83.

19. Kaptanoğlu M, Nadir A. Acquired tracheal lesions in childhood and its surgical management. Türkiye Klinikleri J Surg Med Sci 2006; 2: 22-26.

20. Fitton C. Nursıng management of a child with a tracheostomy. Pediatr Clin North Am 1994; 41(3): 513-23.

21. Barnes LP. Tracheostomy care: preparing parents for discharge. MCN Am J Matern Child Nurs 1992; 17(6): 293. 